\title{
Erratum
}

\section{Erratum: Chariker et al., "Rhythm and Synchrony in a Cortical Network Model"}

In the article "Rhythm and Synchrony in a Cortical Network Model" by Logan Chariker, Robert Shapley, and Lai-Sang Young, which appeared on pages 8621-8634 of the October 3, 2018 issue, the position of the diagrams of PING and REI models on page 8627 are in the wrong place with respect to the text, and the text references to the diagrams are incorrect in the PDF version. The HTML version is correct. The PDF has been updated to match the correct HTML version.

DOI: 10.1523/JNEUROSCI.2901-18.2018 